\title{
An Overview of Recent Studies on the Development of Desiccant Air-conditioning Systems
}

\author{
H. Fatahian ${ }^{1}$, H. Salarian ${ }^{1}$ and E. Fatahian $^{1 *}$ \\ ${ }^{1}$ Department of Mechanical Engineering, Nour Branch, Islamic Azad University, Nour, Iran \\ ${ }^{*}$ Email: esmaeelfatahian@gmail.com
}

\begin{abstract}
In the past decades, desiccant cooling systems have received much attention. These systems are considered as an alternative way to decrease energy consumption and greenhouse gas emission in humid and hot locations. To address the importance of desiccant air-conditioning systems, the present research aims to provide an overview of recent studies on the development of desiccant air conditioning system. Another objective is to consider the numerical and theoretical analysis of desiccant systems. Moreover, for the first time, a summary of recent researches regarding the use of Computational Fluid Dynamics (CFD) technique for numerical modeling of desiccant cooling systems has been especially reviewed in detail. Finally, in the present review, the principle of regeneration of liquid desiccant using solar energy have also been considered briefly.
\end{abstract}

Indexed Terms- Desiccant; Solar energy; Regeneration, Numerical analysis, Greenhouse gas emission.

\section{INTRODUCTION}

Renewable energy is expected to meet around 30\% of global energy demand by 2040 which is demonstrated in Figure 1 [1]. Solar energy contributes a considerable portion to the predicted share of renewable energy. Desiccant dehumidification system can use solar energy for the regeneration of its desiccant. Thus, it is an attractive alternative to Conventional Air Conditioning (CAC) system for humidity control [2]. The desiccant dehumidification processes involve removing water vapor from the air by absorbing it in the desiccant which is hygroscopic in nature. It is substantial to reduce the energy cost of Heating, Ventilating and Air Conditioning (HVAC) system without compromising indoor air quality and comfort condition because of increasing cost of fossil fuel and other environmental concerns [3]. In the past decades, desiccant cooling system has received much attention. This system is considered as an alternative way to reduce energy consumption and greenhouse gas emission in humid and hot locations [4-6]. Researchers indicate that this system can reduce total consuming of energy by shifting the energy used away from electricity and towards renewable, cheaper fuels and waste energy that are pleasant for solar energy [7,8]. Desiccant can absorb water moisture, so they employed positively to overcome the latent part of cooling load.

The present review paper focused on the recent studies on the development of desiccant airconditioning systems, numerical and theoretical analysis of desiccant systems, especially using CFD method for numerical modeling of liquid and solid desiccants, and finally summarizing significant works on the regeneration of liquid desiccant using solar energy.

\section{DESICCANTS AIR-CONDITIONING SYSTEM}

As desiccants can be either solid or liquid [9], they can be categorized into solid desiccant systems, which include fixed bed type and rotary wheel type, and liquid desiccant system. Silica gel, $\mathrm{LiCl}$, molecular sieves, etc. are commonly utilized as solid desiccants. Solid desiccant cooling systems operate on the principle of adsorption of water vapor from the air. In solid desiccant cooling 
systems, the moisture in ventilated/recirculated process air is first removed by a rotating desiccant wheel [10]. The energy required for regeneration of rotary desiccant wheel is supplied through regeneration heat source either by an electrical heater or solar/waste heat. Desiccant cooling systems, hence, comprise principally four components, namely the regeneration heat source, the rotary dehumidifier, sensible heat exchanger, and the cooling unit (Figure 2). The possible configuration and composition of each of the four components can change largely according to the nature of the desiccant [10].

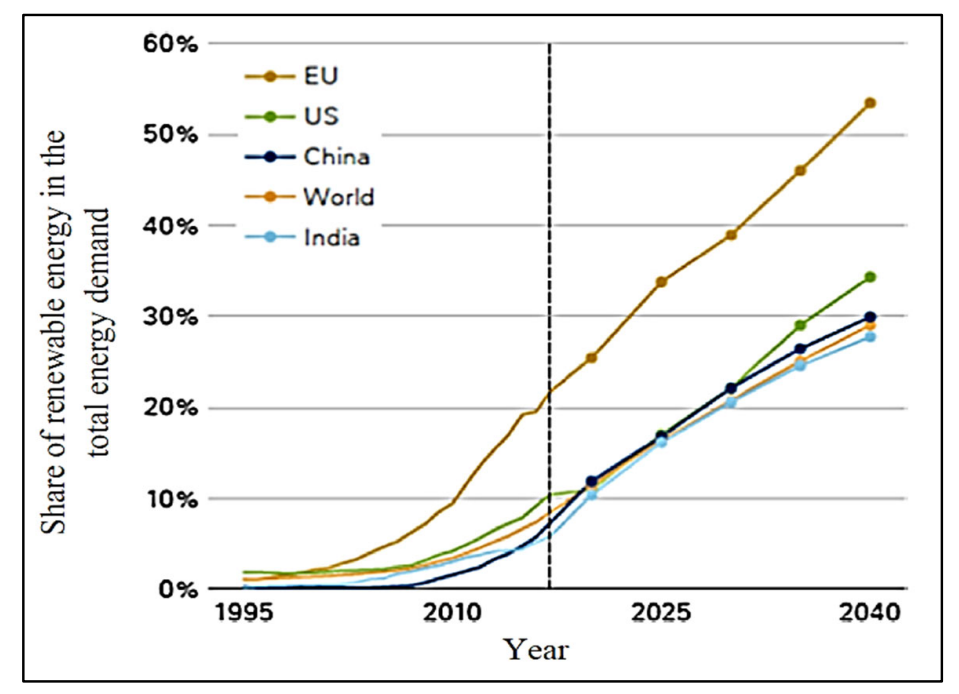

Figure 1: Share of renewable energy [1].

Liquid desiccant has some advantages over solid desiccants [11,12]. The basic sections of the liquid desiccant system including the dehumidifier, regenerator, cooling coil, heating coil, and solution heat exchanger that is shown in Figure 3a [2]. The liquid desiccant solution is the major operating fluid in this system which is used to absorb/desorb water vapor from/to an air stream (Figure 3b) [2]. The liquid desiccant system is more energy-efficient and provides effective control of indoor air humidity [13]. Most liquid desiccant units are direct contact type in which air comes in direct contact with desiccant solution [14].

The problem of carryover of the desiccant solution is a major problem in these direct contact type units. The problem of carryover will affect the indoor air quality and will also raise the cost of maintenance due to corrosion [16]. Abdel-Salametal. [15] introduced a new kind of liquid air membrane energy exchanger as the dehumidifier for avoiding the problem of desiccant solution carryover. The results under fully developed conditions give a system coefficient of performance of 0.6 and humidifier sensible heat ratio of 0.3-0.5. Bichowsky [3] used lithium chloride ( $\mathrm{LiCl}$ ) solution for the aim of drying the air. Some parameters which depict desiccant materials performance are energy storage density, temperature for regeneration, boiling point elevation, availability, and cost. Furthermore, a good desiccant should have these properties including low viscosity, high heat transfer, non-toxic, non-flammable, stable, and inexpensive [3]. Commonly used liquid desiccants in the industrial dehumidifiers are glycols and solutions of halide salts that include lithium chloride $(\mathrm{LiCl})$, lithium bromide $(\mathrm{LiBr})$, calcium chloride $\left(\mathrm{CaCl}_{2}\right)$, and a mixture of salts, etc. Zuber et al. [17] and Ahmed et al. [18] presented thermodynamic characteristics of a single desiccant. They found that lithium chloride has the lowest vapor pressure but it is very expensive as compared to the other ones. Park et al. [19] experimentally studied four 8-C alcohol additives to liquid desiccant to lower its surface vapor pressure. Ertas et al. [20] stated that the viscosity of the mixture of $\mathrm{LiCl}$ and $\mathrm{CaCl}_{2}$ is low and it is highly soluble. Liu et al. [21] considered the performance of two liquid desiccants that 
are commonly used. Moreover, they investigated the reason for replacing triethylene glycol with other aqueous salts. triethylene glycol

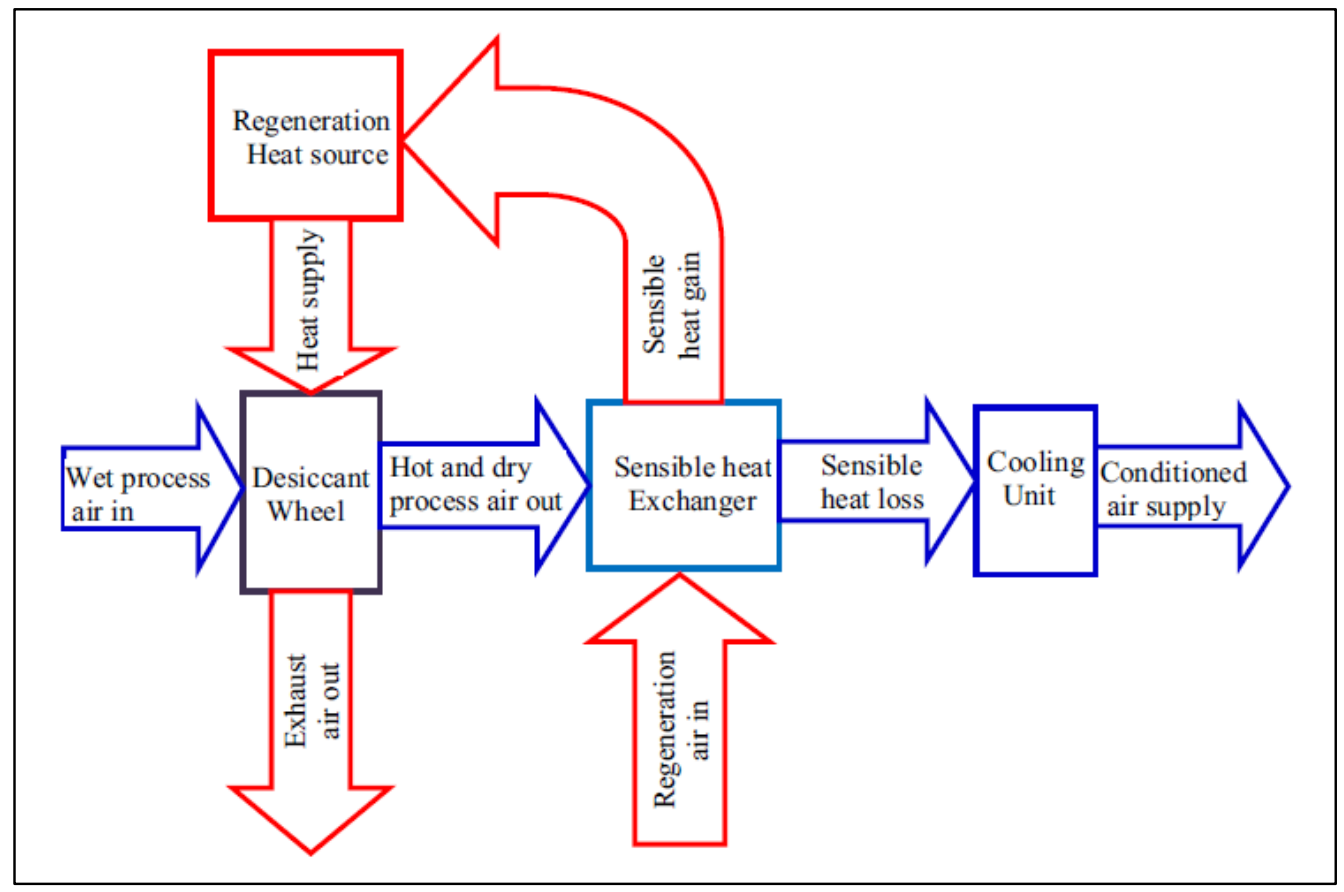

Figure 2: Solid desiccant cooling system [10].

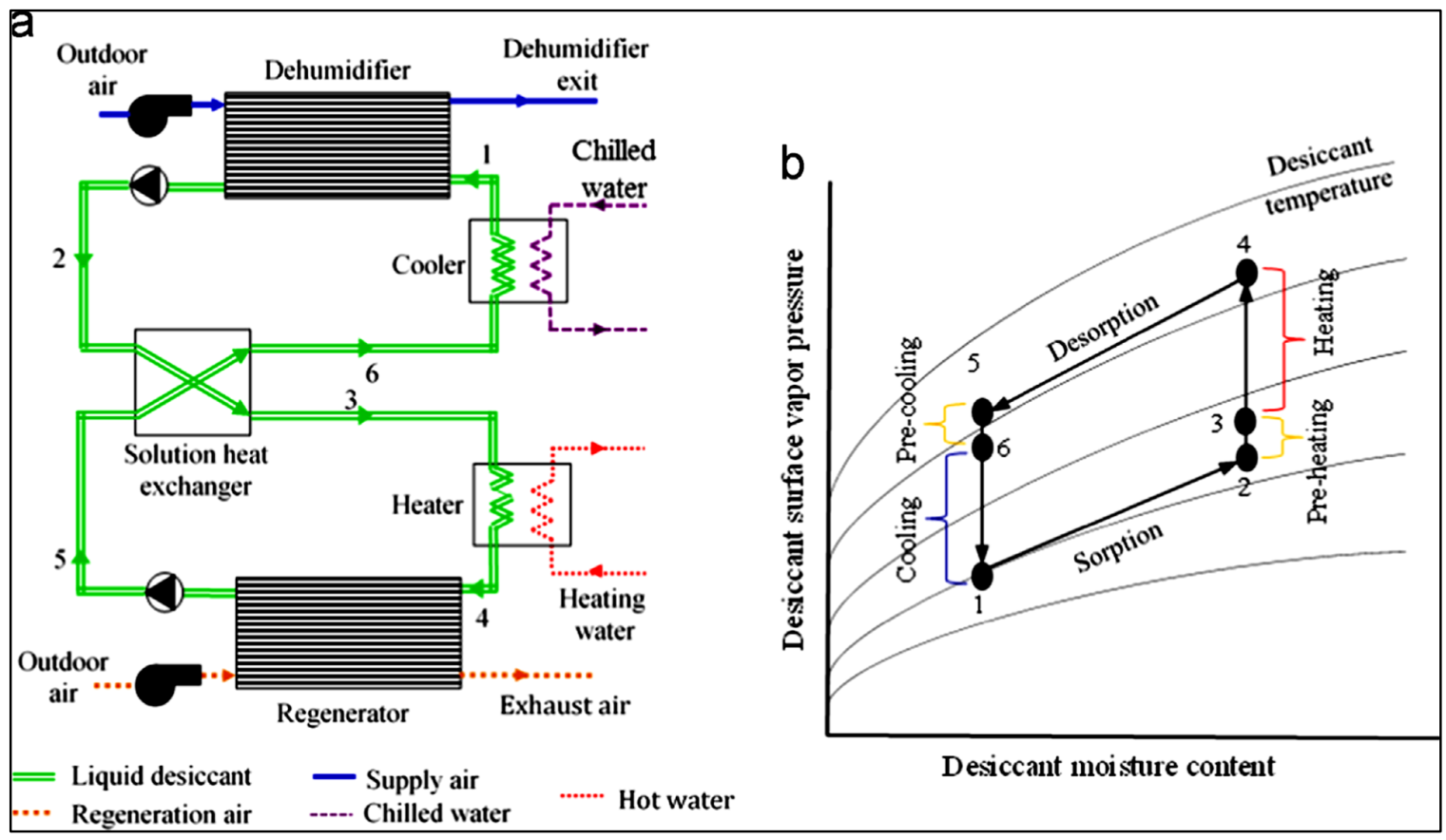

Figure 3: (a) Liquid desiccant system (b) Liquid desiccant cycle [2,15]. 


\section{NUMERICAL AND THEORETICAL ANALYSIS OF DESICCANT SYSTEMS}

The prediction and analysis of fluid flow and heat transfer can be derived by CFD simulation relating to continuity and momentum equations as well as energy equation [22,23]. This numerical investigation can be implemented using Ansys Fluent [24] based on CFD code which is carried out to describe the complex behavior of heat and mass transfer in the absorption and separation process and analyzing the fluid flow and heat transfer in different problems [25-34]. The absorption process of liquid desiccant dehumidifier considered with the CFD technique is rarely presented. Guo et al. [35] used a transient model with the CFD technique to analyze the dynamic performance of a liquid desiccant regenerator. They concluded that the impact of inlet air temperature on the regeneration process was relatively smaller compared to other factors. Also, they found that the mass fraction of water vapor at the air outlet raised with the increment of inlet solution temperature (Figure 4) [35]. The outlet air temperature increased as the inlet solution temperature raised, resulting from the sensible heat and latent heat exchange with the desiccant solution.

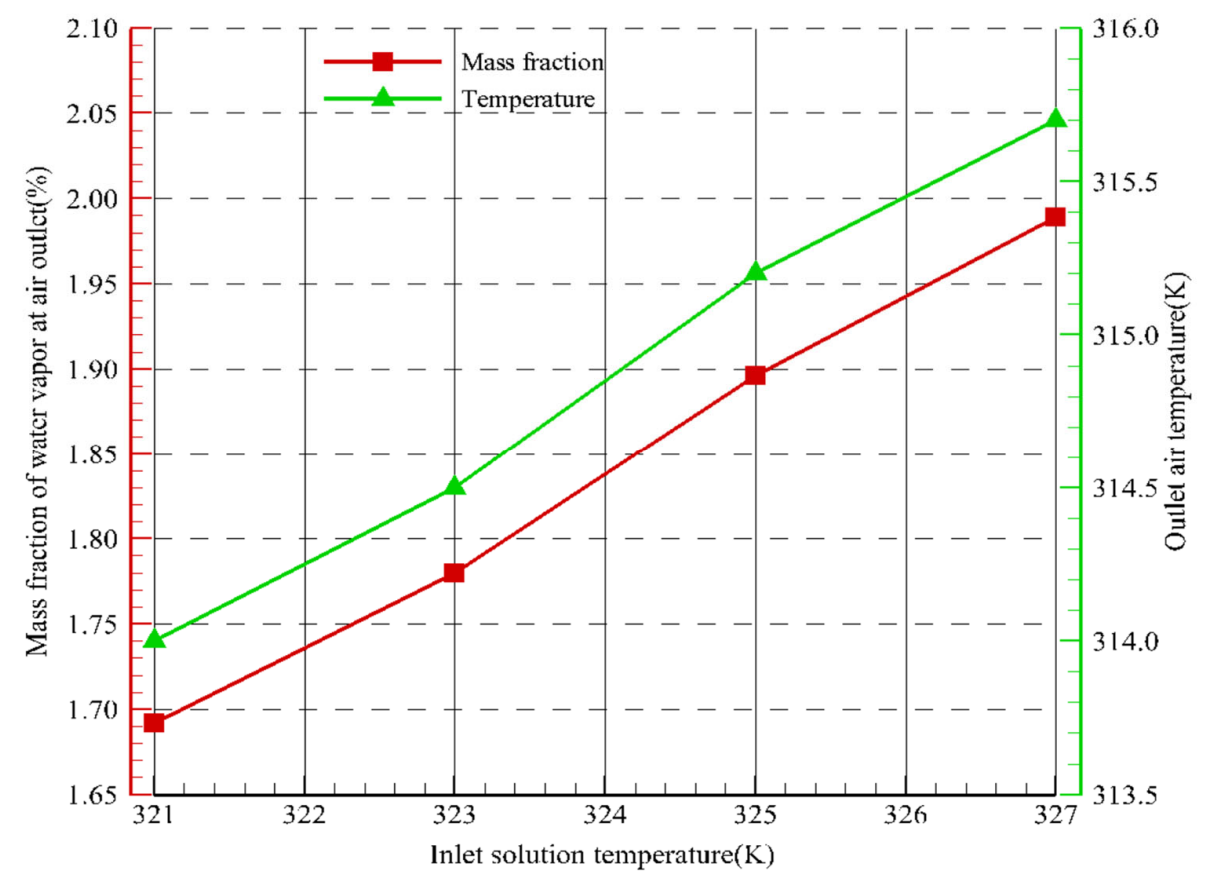

Figure 4: Mass fraction of water vapor under different inlet solution temperature [35].

Bonello et al. [36] implemented a CFD model as a predictive tool for the transient characteristics of silica gel under different operational conditions such as ambient temperature, ambient humidity, supply airflow, and mass of desiccant. Their CFD results accurately predicted the dehumidification performance of changing silica gel masses by using only an experimental test. Luo et al. [37] numerically investigated the flow in liquid desiccant dehumidifier using a CFD-based analysis. They demonstrated that the model successfully predicted the optimum flow rates of solution and air. It was concluded in the study of Luo et al. [38], for optimizing the operating condition, the air velocity should be set based on the channel size, including the channel length and width. Also, they concluded that the CFD model has been proved to be reliable because of good agreement results with the other models. Wen et al. [39] introduced a 3D CFD model of heat and mass transfer process in a falling film dehumidifier. They showed that the non-wetting of falling film and mass transfer resistance in the airside hindered the dehumidification performance. As a result, the CFD simulations have been proved to be reliable to simulate and analyze the dehumidification process. Niu et al. [40] employed a 
standard turbulence model and Discrete Phase Model (DPM) to simulate the heat and mass transfer in a humidification evaporator and consider the velocity and temperature fields in the device. They indicated that the velocity of air was higher under the pipe bundle and there was a partial eddy current near the wall of the box (Figure 5a). The air velocity at the center of the eddy current was higher than in the surrounding area. Figure $5 \mathrm{~b}$ depicts that the total air pressure reduced gradually from the bottom to the top, and was higher under the pipe bundle [40].

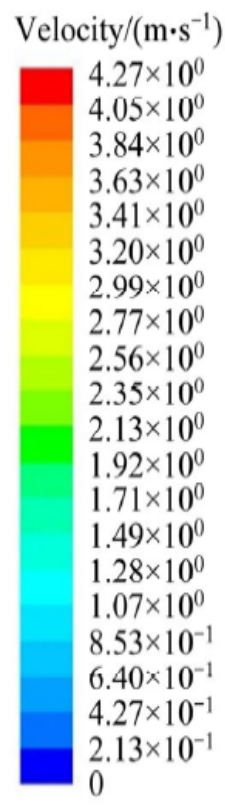

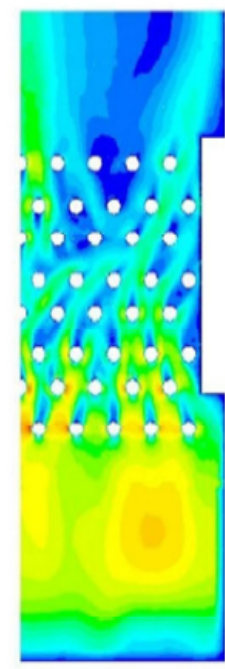

(a)

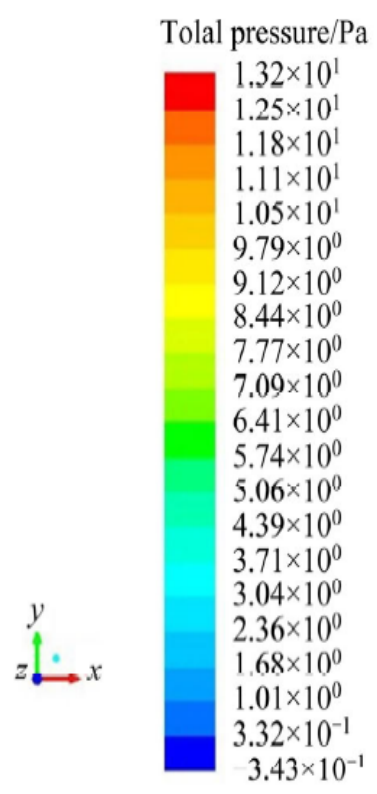

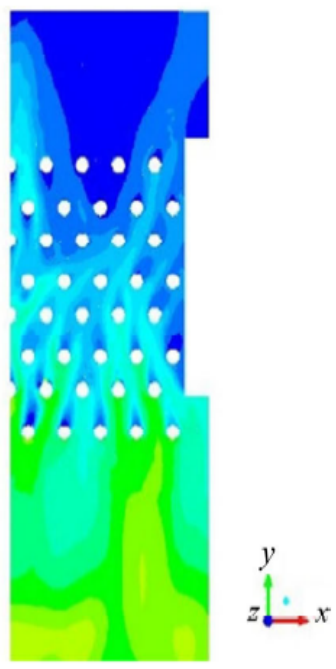

(b)

Figure 5: (a) Airflow velocity vector (b) Total air pressure [40].

Luo et al. [41] introduced some mathematical models to predict and investigate the heat and mass transfer process in a liquid desiccant dehumidifier. The finite-difference model, effectiveness NTU model, and simple analytical model are used commonly in dehumidifier [42]. Different mathematical models are indicated in Table 1. Salarian et al. [43] analytically studied the performance of packedtower dehumidifiers. They considered the impact of dimensionless parameter air to liquid desiccant flow rate ratio (ASMR) on its performance. It can be observed from Figure 6, there is an optimum number for the efficiency of enthalpy which is useful in the design of dehumidifier and regenerator.

Table 1: Mathematical model.

\begin{tabular}{|c|c|c|}
\hline Model & Flow & References \\
\hline Effectiveness NTU model & Counter & {$[43,44]$} \\
\hline Simple/quick prediction & Counter & {$[45]$} \\
\hline Empirical correlations & Cross & {$[46]$} \\
\hline Artificial neural network & Counter & {$[47]$} \\
\hline The kinetic mass transfer model & Cross & {$[48]$} \\
\hline Simple hybrid model & Counter & {$[49]$} \\
\hline $\begin{array}{c}\text { Runge-Kutta based model } \\
\text { fixed step method }\end{array}$ & Counter & {$[50]$} \\
\hline Simple analytical & Cross & {$[52,53]$} \\
\hline Simple analytical & Counter & \\
\hline
\end{tabular}




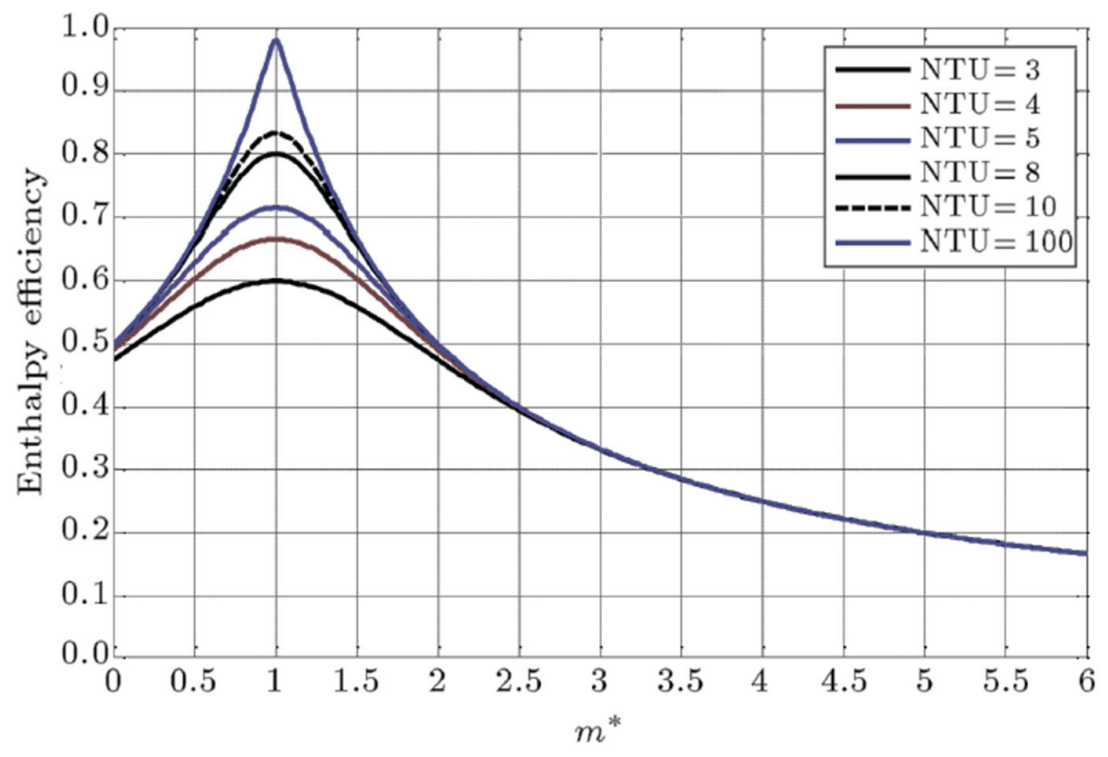

Figure 6: Enthalpy efficiency in terms of $\mathrm{m}^{*}[43]$.

Qi et al. [52] analytically investigated a theoretical model for predicting the falling film desiccant dehumidification process. Consequently, it is theoretically possible to evaluate the characteristics of liquid/air interface with heat and mass transfer. Liu et al. [53] validated a simple analytical solution for heat and mass transfer of a liquid desiccant dehumidifier. They found that the enthalpy efficiency of the dehumidifier equaled moisture efficiency.

\section{REGENERATION OF LIQUID DESICCANT USING SOLAR ENERGY}

Increased population, improved economy, comparatively lower cost of air conditioning equipment for more suitable human conditions are imposing major stress on our electricity production house [54,55]. Air conditioners mainly operate on Vapour Compression Refrigeration System (VCRS), which consumes a large amount of electrical energy. Solar cooling is a significant solution to global warming and environmental degradation [56-60]. The major option to the conventional VCRS is solar used Liquid Desiccant (LD) dehumidification followed by evaporative water cooling. In liquid desiccant based air conditioning, after the adsorption of moisture from process air LD requires to be regenerated. This weak liquid desiccant solution can be regenerated by heating by using solar radiation [61]. This heat can be supplied by solar-heated air in the stripping column or with the help of various process solar equipment e.g. solar still [62-64], solar collector [65,66], falling film [67], packed bed [68], solar dryer [69], solar pond [70], etc.

A solar-powered liquid desiccant system having an evaporative pad for greenhouse food production application in hot and humid climates as illustrated in Figure 7 [71]. As an alternative option of Solid Desiccant Cooling Systems (SDCS), Liquid Desiccant Air conditioning (LDAC) systems have emerged rapidly in the last few years. The lower regeneration temperature around 45-70 ${ }^{\circ} \mathrm{C}[72,73]$ allows liquid desiccant to be applied in the air conditioning system rather than solid desiccant having a temperature range of $70-120^{\circ} \mathrm{C}[74]$. 


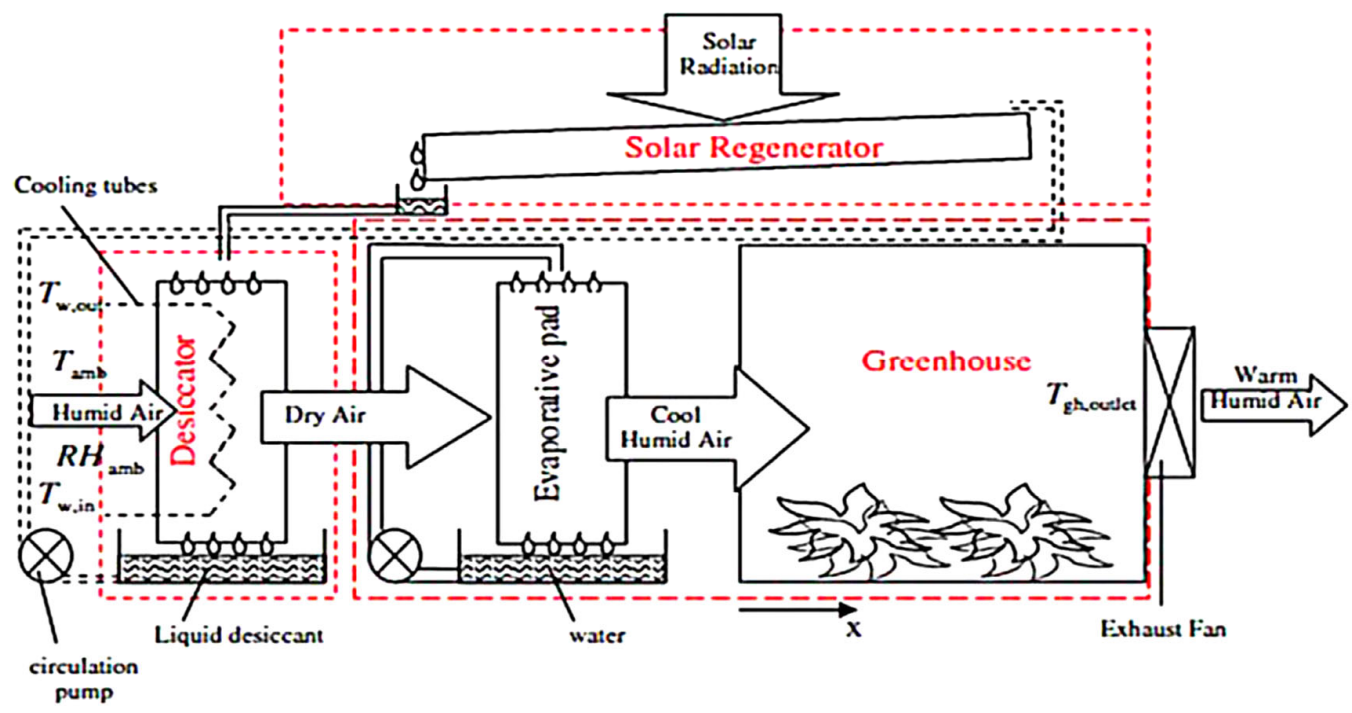

Figure 7: Solar used liquid desiccant dehumidification [71].

As a kind of renewable energy, solar energy can be utilized for regenerating liquid desiccant and solar desiccant regeneration system has attracted much attention [75,76]. At present, the solar desiccant regeneration system is mainly driven by solar thermal energy (TH regeneration) [77]. The solar collector/regenerator, which combines solar collector and regenerator of solar desiccant regeneration system, has been investigated by many researchers [78-80]. Katejanekarn et al. [81] have experimentally considered the performance of a Solar regenerated liquid desiccant ventilation preconditioning system in all-year-round seasons containing winter, summer, and rain as depicted in Figure 8 . They concluded the reduction in temperature around $1.2{ }^{\circ} \mathrm{C}$ with a total humidity reduction of about $11 \%$.

Kabeel [82] investigated the regeneration of liquid solution using cross-flow of air stream with a flowing film of desiccant on the surface of a solar collector/regenerator. Their results indicated that the enhancement of regeneration efficiency for the forced cross-flow compared with the free regeneration. Li and Yang [83] analyzed the energy performance for using exhaust air for the regeneration of weak desiccant solution and heating the solution to a temperature higher than the equilibrium value for different lengths of the collector/regenerator panels. They concluded that the thermodynamic performance is substantially improved and it is possible to shorten the length of the solar collector/regenerator without degrading the performance greatly. Mehta et al. [84] used a novel Evacuated Type Collector (ETC) as a regenerator for a liquid desiccant-based solar air conditioning system. This non-tracking type ETC can obtain more range of temperature than a conventional solar flat plate collector and liquid can be boiled in it. 


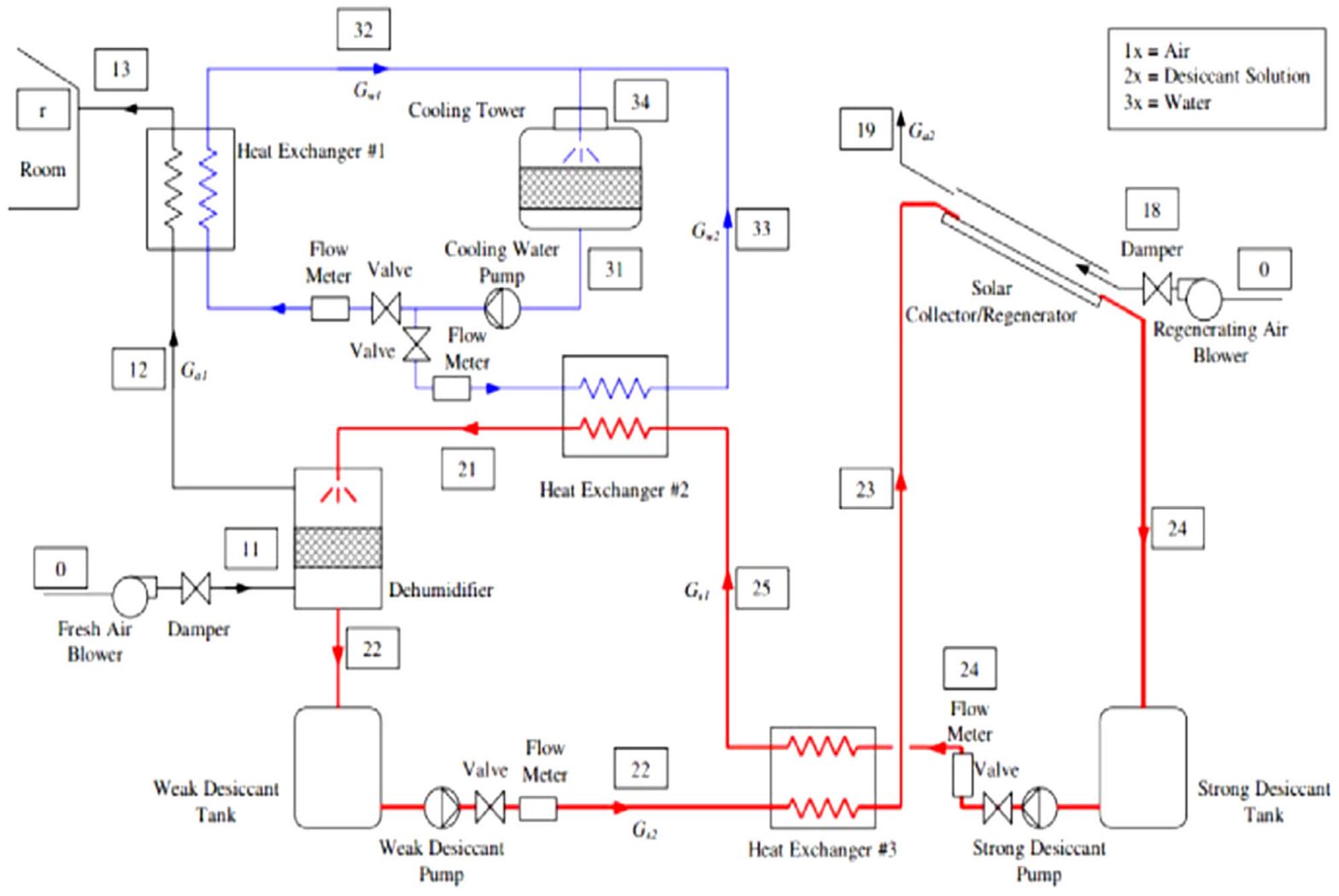

Figure 8: Solar regenerated liquid desiccant ventilation pre-conditioning system [81].

\section{CONCLUSION}

This review provides a comprehensive overview of the developments of the desiccant air conditioning system. It explained the numerical and theoretical analysis of desiccant systems. Furthermore, a summary of recent studies regarding the use of the CFD method for numerical analysis of desiccant systems was reviewed. Finally, the regeneration of liquid desiccant using solar energy was considered in detail. The conclusions emerging from reviewing recent studies can be summarized as:

- Desiccant dehumidification system is an attractive alternative to Conventional Air Conditioning (CAC) systems for humidity control.

- Liquid desiccant has more advantages over solid desiccants.

- The liquid desiccant systems are more energy-efficient and provide effective control of indoor air humidity.

- Most of the liquid desiccant units are direct contact type in which air comes in direct contact with the desiccant solution.

- CFD method has been proved to be reliable in order to simulate the desiccant dehumidification system.

- The finite-difference model, effectiveness NTU model, and simple analytical model are used commonly in a desiccant dehumidifier.

- In liquid desiccant based air conditioning, after the adsorption of moisture from process air liquid desiccant needs to be regenerated which can be regenerated by heating with the help of solar radiation. 


\section{REFERENCES}

[1] Gurubalan, A., Maiya, M. P., \& Geoghegan, P. J. (2019). A comprehensive review of liquid desiccant air conditioning system. Applied Energy, 254, 113673.

[2] Abdel-Salam, A. H., \& Simonson, C. J. (2016). State-of-the-art in liquid desiccant air conditioning equipment and systems. Renewable and Sustainable Energy Reviews, 58, 1152-1183.

[3] Rafique, M. M., Gandhidasan, P., \& Bahaidarah, H. M. (2016). Liquid desiccant materials and dehumidifiers-A review. Renewable and Sustainable Energy Reviews, 56, 179-195.

[4] Lin, J., Huang, S. M., Wang, R., \& Chua, K. J. (2019). On the in-depth scaling and dimensional analysis of a cross-flow membrane liquid desiccant dehumidifier. Applied Energy, 250, 786-800.

[5] Dong, C., Qi, R., Zhang, L., \& Lu, L. (2019). Performance enhancement of solar-assisted liquid desiccant dehumidifiers using super-hydrophilic surface. Energy and Buildings, 199, 461-471.

[6] Chen, Y., Yang, H., \& Luo, Y. (2018). Investigation on solar assisted liquid desiccant dehumidifier and evaporative cooling system for fresh air treatment. Energy, 143, 114-127.

[7] Daou, K., Wang, R. Z., \& Xia, Z. Z. (2006). Desiccant cooling air conditioning: a review. Renewable and Sustainable Energy Reviews, 10(2), 55-77.

[8] Gommed, K., \& Grossman, G. (2004). A liquid desiccant system for solar cooling and dehumidification. Journal of Solar Energy Engineering, 126(3), 879-885.

[9] Kinsara, A. A., Al-Rabghi, O. M., \& Elsayed, M. M. (1998). Parametric study of an energy efficient air conditioning system using liquid desiccant. Applied Thermal Engineering, 18(5), 327335.

[10] Jani, D. B., Mishra, M., \& Sahoo, P. K. (2016). Solid desiccant air conditioning-A state of the art review. Renewable and Sustainable Energy Reviews, 60, 1451-1469

[11] Baniyounes, A. M., Ghadi, Y. Y., Rasul, M. G., \& Khan, M. M. K. (2013). An overview of solar assisted air conditioning in Queensland's subtropical regions, Australia. Renewable and Sustainable Energy Reviews, 26, 781-804.

[12] Kinsara, A. A., Elsayed, M. M., \& Al-Rabghi, O. M. (1996). Proposed energy-efficient airconditioning system using liquid desiccant. Applied Thermal Engineering, 16(10), 791-806.

[13] Qi, R., Lu, L., \& Yang, H. (2012). Investigation on air-conditioning load profile and energy consumption of desiccant cooling system for commercial buildings in Hong Kong. Energy and Buildings, 49, 509-518.

[14] Harriman III, L. G., Plager, D., \& Kosar, D. (1997). Dehumidification and cooling loads from ventilation air. ASHRAE journal, 39(11), 6-15.

[15] Abdel-Salam, A. H., Ge, G., \& Simonson, C. J. (2013). Performance analysis of a membrane liquid desiccant air-conditioning system. Energy and Buildings, 62, 559-569.

[16] Burns, P. R., Mitchell, J. W., \& Beckman, W. A. (1985). Hybrid desiccant cooling systems in supermarket applications. ASHRAE transactions, 91(1), 457-468.

[17] Zuber, A., Checoni, R. F., Mathew, R., Santos, J. P. L., Tavares, F. W., \& Castier, M. (2013). Thermodynamic properties of 1: 1 salt aqueous solutions with the electrolattice equation of state. Oil \& Gas Science and Technology-Revue d'IFP Energies nouvelles, 68(2), 255-270.

[18] Ahmed, S. Y., Gandhidasan, P., \& Al-Farayedhi, A. A. (1998). Thermodynamic analysis of liquid desiccants. Solar Energy, 62(1), 11-18.

[19] Park, Y., Kim, J. S., \& Lee, H. (1997). Physical properties of the lithium bromide+ 1, 3propanediol+ water system. International journal of refrigeration, 20(5), 319-325.

[20] Ertas, A., Anderson, E. E., \& Kiris, I. (1992). Properties of a new liquid desiccant solutionlithium chloride and calcium chloride mixture. Solar Energy, 49(3), 205-212.

[21] Liu, X. H., Yi, X. Q., \& Jiang, Y. (2011). Mass transfer performance comparison of two commonly used liquid desiccants: $\mathrm{LiBr}$ and $\mathrm{LiCl}$ aqueous solutions. Energy Conversion and management, 52(1), 180-190.

[22] Augier, F., Masbernat, O., \& Guiraud, P. (2003). Slip velocity and drag law in a liquid-liquid homogeneous dispersed flow. AIChE journal, 49(9), 2300-2316. 
[23] Fatahian, E., Kordani, N., \& Fatahian, H. (2018). The Application of Computational Fluid Dynamics (CFD) Method and Several Rheological Models of Blood Flow: A Review. Gazi University Journal of Science, 31(4), 1213-1227.

[24] Fluent, A. (2009). 12.0 User's guide. Ansys inc, 6.

[25] Luo, Y., Yang, H., \& Lu, L. (2014). Dynamic and microscopic simulation of the counter-current flow in a liquid desiccant dehumidifier. Applied Energy, 136, 1018-1025.

[26] Fatahian, E., Salarian, H., \& Fatahian, H. (2020). Numerical Investigation of Hazardous Gas Dispersion Over Obstacles and Residential Areas. International Journal of Engineering, 33(10), 2087-2094.

[27] Fatahian, H., Hosseini, E., \& Fatahian, E. (2020). CFD simulation of a novel design of square cyclone with dual-inverse cone. Advanced Powder Technology, 31(4), 1748-1758.

[28] Luo, Y., Chen, Y., Yang, H., \& Wang, Y. (2017). Study on an internally-cooled liquid desiccant dehumidifier with CFD model. Applied Energy, 194, 399-409.

[29] Fatahian, E., Salarian, H., \& Fatahian, H. (2020). A parametric study of the heat exchanger copper coils used in an indirect evaporative cooling system. SN Applied Sciences, 2(1), 1-10.

[30] Fatahian, H., Salarian, H., Nimvari, M. E., \& Fatahian, E. (2018). Numerical study of thermal characteristics of fuel oil-alumina and water-alumina nanofluids flow in a channel in the laminar flow. IIUM Engineering Journal, 19(1), 251-269.

[31] Fatahian, E., Nichkoohi, A. L., \& Fatahian, H. (2019). Numerical study of the effect of suction at a compressible and high Reynolds number flow to control the flow separation over Naca 2415 airfoil. Progress in Computational Fluid Dynamics, an International Journal, 19(3), 170-179.

[32] Fatahian, H., Salarian, H., Nimvari, M. E., \& Fatahian, E. (2018). Numerical study of suction and blowing approaches to control flow over a compressor cascade in turbulent flow regime. International Journal of Automotive and Mechanical Engineering, 15(2), 5326-5346.

[33] Lin, J., Huang, S., Wang, R., \& Chua, K. J. (2019). On the dimensional analysis of a cross-flow flat-plate membrane liquid desiccant dehumidifier. Energy Procedia, 158, 1467-1472.

[34] Fatahian, H., Fatahian, E., \& Nimvari, M. E. (2018). Improving efficiency of conventional and square cyclones using different configurations of the laminarizer. Powder technology, 339, 232-243.

[35] Guo, X., Wen, T., Wang, M., Luo, Y., \& She, X. (2020). Performance investigation of a liquid desiccant regenerator with CFD technology. Applied Thermal Engineering, 116055.

[36] Bonello, M., Micallef, D., \& Borg, S. P. (2019). Flat bed desiccant dehumidification: A predictive model for desiccant transient characterisation using a species transport model within CFD. Journal of Building Engineering, 23, 280-290.

[37] Luo, Y., Yang, H., \& Lu, L. (2014). Dynamic and microscopic simulation of the counter-current flow in a liquid desiccant dehumidifier. Applied energy, 136, 1018-1025.

[38] Luo, Y., Yang, H., \& Lu, L. (2014). Liquid desiccant dehumidifier: Development of a new performance predication model based on CFD. International Journal of Heat and Mass Transfer, 69, 408-416.

[39] Wen, T., Luo, Y., He, W., Gang, W., \& Sheng, L. (2019). Development of a novel quasi-3D model to investigate the performance of a falling film dehumidifier with CFD technology. International Journal of Heat and Mass Transfer, 132, 431-442.

[40] Niu, R. P., Chen, X. Y., Wang, Z. Y., \& Kuang, D. Q. (2019). Numerical simulation of liquid desiccant evaporator driven by heat pump. Journal of Central South University, 26(8), 2197-2213.

[41] Luo, Y., Yang, H., Lu, L., \& Qi, R. (2014). A review of the mathematical models for predicting the heat and mass transfer process in the liquid desiccant dehumidifier. Renewable and Sustainable Energy Reviews, 31, 587-599.

[42] Kumar, R., \& Asati, A. K. (2014). Simplified mathematical modelling of dehumidifier and regenerator of liquid desiccant system. International Journal of Current Engineering and Technology, 4, 557-563. 
[43] Salarian, H., Ghorbani, B., Amidpour, M., \& Salehi, G. (2014). Performance study on the dehumidifier of a packed bed liquid desiccant system. Scientia Iranica. Transaction B, Mechanical Engineering, 21(1), 222-228.

[44] Stevens, D. I., Braun, J. E., \& Klein, S. A. (1989). An effectiveness model of liquid-desiccant system heat/mass exchangers. Solar Energy, 42(6), 449-455.

[45] Gandhidasan, P. (2005). Quick performance prediction of liquid desiccant regeneration in a packed bed. Solar Energy, 79(1), 47-55.

[46] Liu, X. H., Qu, K. Y., \& Jiang, Y. (2006). Empirical correlations to predict the performance of the dehumidifier using liquid desiccant in heat and mass transfer. Renewable Energy, 31(10), 16271639.

[47] Gandhidasan, P., \& Mohandes, M. A. (2011). Artificial neural network analysis of liquid desiccant dehumidification system. Energy, 36(2), 1180-1186.

[48] Li, X. W., Zhang, X. S., \& Wang, F. (2013). A kinetic mass transfer model of liquid dehumidification for liquid desiccant cooling system. Energy and Buildings, 61, 93-99.

[49] Wang, X., Cai, W., Lu, J., Sun, Y., \& Ding, X. (2013). A hybrid dehumidifier model for realtime performance monitoring, control and optimization in liquid desiccant dehumidification system. Applied energy, 111, 449-455.

[50] Koronaki, I. P., Christodoulaki, R. I., Papaefthimiou, V. D., \& Rogdakis, E. D. (2013). Thermodynamic analysis of a counter flow adiabatic dehumidifier with different liquid desiccant materials. Applied Thermal Engineering, 50(1), 361-373.

[51] Bassuoni, M. M. (2014). A simple analytical method to estimate all exit parameters of a crossflow air dehumidifier using liquid desiccant. Journal of advanced research, 5(2), 175-182.

[52] Qi, R., Dong, C., \& Zhang, L. Z. (2019). Wave-wise falling film in liquid desiccant dehumidification systems: Model development and time-series parameter analysis. International Journal of Heat and Mass Transfer, 132, 96-106.

[53] Liu, J., Liu, X., \& Zhang, T. (2019). Analytical solution of heat and mass transfer process in internally cooled liquid desiccant dehumidifiers using refrigerant as cooling medium. Energy and Buildings, 190, 1-14.

[54] Kodama, A., Ohkura, M., Hirose, T., Goto, M., \& Okan, H. (2005). An energy flow analysis of a solar desiccant cooling equipped with a honeycomb adsorber. Adsorption, 11(1), 597-602.

[55] Mei, L., \& Dai, Y. J. (2008). A technical review on use of liquid-desiccant dehumidification for air-conditioning application. Renewable and Sustainable Energy Reviews, 12(3), 662-689.

[56] Li, Y., Lu, L., \& Yang, H. (2010). Energy and economic performance analysis of an open cycle solar desiccant dehumidification air-conditioning system for application in Hong Kong. Solar Energy, 84(12), 2085-2095.

[57] Halliday, S. P., Beggs, C. B., \& Sleigh, P. A. (2002). The use of solar desiccant cooling in the UK: a feasibility study. Applied Thermal Engineering, 22(12), 1327-1338.

[58] Mavroudaki, P., Beggs, C. B., Sleigh, P. A., \& Halliday, S. P. (2002). The potential for solar powered single-stage desiccant cooling in southern Europe. Applied Thermal Engineering, 22(10), $1129-1140$.

[59] Rayegan, S., Motaghian, S., Heidarinejad, G., Pasdarshahri, H., Ahmadi, P., \& Rosen, M. A. (2020). Dynamic simulation and multi-objective optimization of a solar-assisted desiccant cooling system integrated with ground source renewable energy. Applied Thermal Engineering, 173, 115210.

[60] Habib, M. F., Ali, M., Sheikh, N. A., Badar, A. W., \& Mehmood, S. (2020). Building thermal load management through integration of solar assisted absorption and desiccant air conditioning systems: A model-based simulation-optimization approach. Journal of Building Engineering, 30, 101279.

[61] Cheng, Q., \& Zhang, X. (2013). Review of solar regeneration methods for liquid desiccant airconditioning system. Energy and Buildings, 67, 426-433.

[62] Abdullah, A. S., Younes, M. M., Omara, Z. M., \& Essa, F. A. (2020). New design of trays solar still with enhanced evaporation methods-Comprehensive study. Solar Energy, 203, 164-174. 
[63] Kabeel, A. E., Harby, K., Abdelgaied, M., \& Eisa, A. (2020). Performance of the modified tubular solar still integrated with cylindrical parabolic concentrators. Solar Energy, 204, 181-189.

[64] Hassan, H., Yousef, M. S., Fathy, M., \& Ahmed, M. S. (2020). Assessment of parabolic trough solar collector assisted solar still at various saline water mediums via energy, exergy, exergoeconomic, and enviroeconomic approaches. Renewable Energy, 155, 604-616.

[65] Sheikholeslami, M., Farshad, S. A., Shafee, A., \& Babazadeh, H. (2021). Performance of solar collector with turbulator involving nanomaterial turbulent regime. Renewable Energy, 163, 12221237.

[66] Olfian, H., Ajarostaghi, S. S. M., Farhadi, M., \& Ramiar, A. (2021). Melting and solidification processes of phase change material in evacuated tube solar collector with U-shaped spirally corrugated tube. Applied Thermal Engineering, 182, 116149.

[67] Jain, S., Dhar, P. L., \& Kaushik, S. C. (2000). Experimental studies on the dehumidifier and regenerator of a liquid desiccant cooling system. Applied Thermal Engineering, 20(3), 253-267.

[68] Sultan, G. I., Hamed, A. M., \& Sultan, A. A. (2002). The effect of inlet parameters on the performance of packed tower-regenerator. Renewable energy, 26(2), 271-283.

[69] Purohit, P., \& Kandpal, T. C. (2005). Solar crop dryer for saving commercial fuels: a technoeconomic evaluation. International journal of ambient energy, 26(1), 3-12.

[70] Kalogirou, S. A. (2005). Seawater desalination using renewable energy sources. Progress in energy and combustion science, 31(3), 242-281.

[71] Lychnos, G., \& Davies, P. A. (2012). Modelling and experimental verification of a solar-powered liquid desiccant cooling system for greenhouse food production in hot climates. Energy, 40(1), 116130.

[72] Li, X. W., Zhang, X. S., \& Quan, S. (2011). Single-stage and double-stage photovoltaic driven regeneration for liquid desiccant cooling system. Applied Energy, 88(12), 4908-4917.

[73] Zurigat, Y. H., Abu-Arabi, M. K., \& Abdul-Wahab, S. A. (2004). Air dehumidification by triethylene glycol desiccant in a packed column. Energy Conversion and Management, 45(1), 141155.

[74] Vineyard, E. A., Sand, J. R., \& Durfee, D. J. (2000). Parametric analysis of variables that affect the performance of a desiccant dehumidification system. ASHRAE Transactions, 106, 87-100.

[75] Katejanekarn, T., Chirarattananon, S., \& Kumar, S. (2009). An experimental study of a solarregenerated liquid desiccant ventilation pre-conditioning system. Solar Energy, 83(6), 920-933.

[76] Elsarrag, E. (2008). Evaporation rate of a novel tilted solar liquid desiccant regeneration system. Solar energy, 82(7), 663-668.

[77] Alosaimy, A. S., \& Hamed, A. M. (2011). Theoretical and experimental investigation on the application of solar water heater coupled with air humidifier for regeneration of liquid desiccant. Energy, 36(7), 3992-4001.

[78] Bhowmik, M., Muthukumar, P., \& Anandalakshmi, R. Experimental study of coupled heat and mass transfer phenomena between air and desiccant in a solar assisted thermal liquid desiccant system. International Journal of Thermal Sciences, 162, 106795.

[79] Sabareesh, V., John, M. K., \& Muraleedharan, C. (2021). Improved solar drying performance by ultrasonic desiccant dehumidification in indirect forced convection solar drying of ginger with phase change material. Renewable Energy.

[80] Chen, Y., Liu, Y., Wang, D., Luo, X., Liu, J., Liu, J., ... \& Liu, J. (2020). Performance and optimization of a novel solar-driven liquid desiccant air conditioning system suitable for extremely hot and humid climates. Energy Conversion and Management, 215, 112899.

[81] Katejanekarn, T., Chirarattananon, S., \& Kumar, S. (2009). An experimental study of a solarregenerated liquid desiccant ventilation pre-conditioning system. Solar Energy, 83(6), 920-933.

[82] Kabeel, A. E. (2005). Augmentation of the performance of solar regenerator of open absorption cooling system. Renewable Energy, 30(3), 327-338. 
[83] Yutong, L., \& Hongxing, Y. (2008). Investigation on solar desiccant dehumidification process for energy conservation of central air-conditioning systems. Applied Thermal Engineering, 28(10), 1118-1126.

[84] Mehta, J. R., \& Rane, M. V. (2013). Liquid desiccant based solar air conditioning system with novel evacuated tube collector as regenerator. Procedia Engineering, 51, 688-693. 